\title{
Beam-Column Joint Retrofitting With High Performance Fiber Reinforced Concrete Jacketing
}

\author{
Consuelo Beschi, \\ Department of Civil Engineering, Architecture, Land and Environment, University of Brescia, via Branze 43, \\ 25123 Brescia, Italy \\ Alberto Meda, \\ Civil Engineering Department, University of Rome “Tor Vergata”, via del Politecnico 1, 00133 Rome, Italy \\ Paolo Riva, \\ Department of Design and Technologies, University of Bergamo v.le Marconi 5, 24044 Dalmine (BG), Italy
}

Keywords: seismic retrofitting; high performance fiber reinforced concrete; beam-to-column joint; existing R.C. frames; cyclic test.

\begin{abstract}
The possibility of strengthening existing R/C structures with a new technique based on the application of a High Performance Fiber Reinforced Concrete jacket is investigated herein, with the aim of studying the effectiveness of this technique for seismic retrofitting.

The results of a beam-column joint full scale test, simulating the behavior of an existing beam-column joint, are presented. The specimen has been subjected first to static loads and then to cyclic actions with increasing amplitude, up to failure. The effects of HPFRC jacketing on beam-column joint behavior are analyzed: the experimental results are compared to analytical evaluations of strength of the retrofitted elements according to the new Italian code, and to the response of the base elements.

The test demonstrated that, with the application of a high performance jacket, it is possible to remarkably increase the bearing capacity of the column and the strength of the beam column joint, reaching also an adequate level of ductility with very little visible damage, thanks to the tensile strength contribution of HPFRC.
\end{abstract}

\section{INTRODUCTION}

Several techniques can be adopted for the seismic retrofitting of existing R.C. elements (Fib Bulletin n. 24, 2003; Fib Bulletin n. 32, 2006; Fib Bulletin n. 35, 2006; Fib Report 1991).

Concerning the strengthening of columns, one possible technique is the casting of R.C. jackets, especially when the elements are made of low strength concrete. It is remarked that R.C. jacketing allows to increase not only the members' strength but also their ductility, due to the confining action. However traditional jacketing presents some inconveniences, due to the jacket thickness being governed by the steel cover (both external and internal). This often leads to a jacket thickness higher than 70-100 $\mathrm{mm}$, with a consequent increase in section geometry and hence in both mass and stiffness, requiring special attention with respect to the overall seismic response of the retrofitted structure. This aspect is important when columns with small sections are considered $(250-300 \mathrm{~mm})$.

For reinforced concrete structures, other retrofitting techniques have been recently developed, such as FRP wrapping. Furthermore, FRP wrapping is useful to enhance ductility, but it is not suitable when a noticeable strength increase of the column is also needed.

In recent years, a new technique based on the use of thin jackets made with High Performance Fiber Reinforced Concrete (HPFRC) has been developed (Martinola et al. 2007, Maisto et al. 2007). The proposed technique consists in encasing structural concrete elements in a thin layer of HPFRC (30-40 mm). The HPFRC material adopted exhibits a hardening behavior in tension coupled with a high compression strength, larger strain capacity and toughness when compared to traditional FRCs, which makes it ideal for the strengthening of members subjected to large inelastic deformation demands. 
As a consequence, given the tensile strength and ductility of the HPFRC layer, the traditional reinforcement in the jacket can be avoided. This technique has been demonstrated effective for the strengthening of existing columns (Meda et al. 2008).

Recent investigations on structures built in Italy around the ' $60 \mathrm{~s}$ and ' $70 \mathrm{~s}$ demonstrated that the average concrete compressive strength is often lower than $15 \mathrm{MPa}$ (Ferrini et al. 2008). In this case, buildings not only may have problems in carrying the design vertical loads but, when a seismic retrofitting is required, have to be significantly strengthened.

Herein the results of an experimental test on a full scale beam-column joint are presented. The test has been carried out as a part of a retrofitting intervention on a school building, located in a seismic area near Rome. Several in situ tests, performed in order to assess the structural details and the strength of concrete and steel, demonstrated that a very weak concrete was used, with an average compressive strength equal of $11 \mathrm{MPa}$.

The assessment of the building was carried out by performing a non linear analysis, which showed that the existing structure was not able to sustain both the static and the seismic loading condition according to the current Italian code requirements (DM 2008, Instruction DM 2008), compatible with current Eurocode requirements (EN 1992-1-1, 2004; EN 1998-1-1, 2004).
Given the above, the designer decided to strengthen the columns and joints both for static and seismic loading by means of a $40 \mathrm{~mm}$ jacket in HPFRC, while the beams were strengthened with FRP sheets in order to enhance the load carrying capacity with respect to static loads.

Before the application of the jackets, two full scale tests simulating the behavior of the existing columns and beam-column joints were required by the Italian Council for Public Works.

Following this request, the University of Bergamo was asked to perform cyclic tests up to failure. The results of the test carried out on the column-foundation joint can be found in Beschi et al. (2009).

Once the results demonstrated the effectiveness of the applied technique, the application in the school building was authorized and eventually executed.

\section{SPECIMEN PREPARATION}

The test specimen was characterized by a column cross section of $300 \times 300 \mathrm{~mm}$ in the upper part and 400x400 $\mathrm{mm}$ in the lower part, while the beam had a 300x600 mm cross section. The column was $3.55 \mathrm{~m}$ high and the beam $5 \mathrm{~m}$ long. To simulate the presence of the transverse beam in the real structure, a R.C. corbel was placed at the beam-column joint. The geometry of the specimen is illustrated in Figure 1.

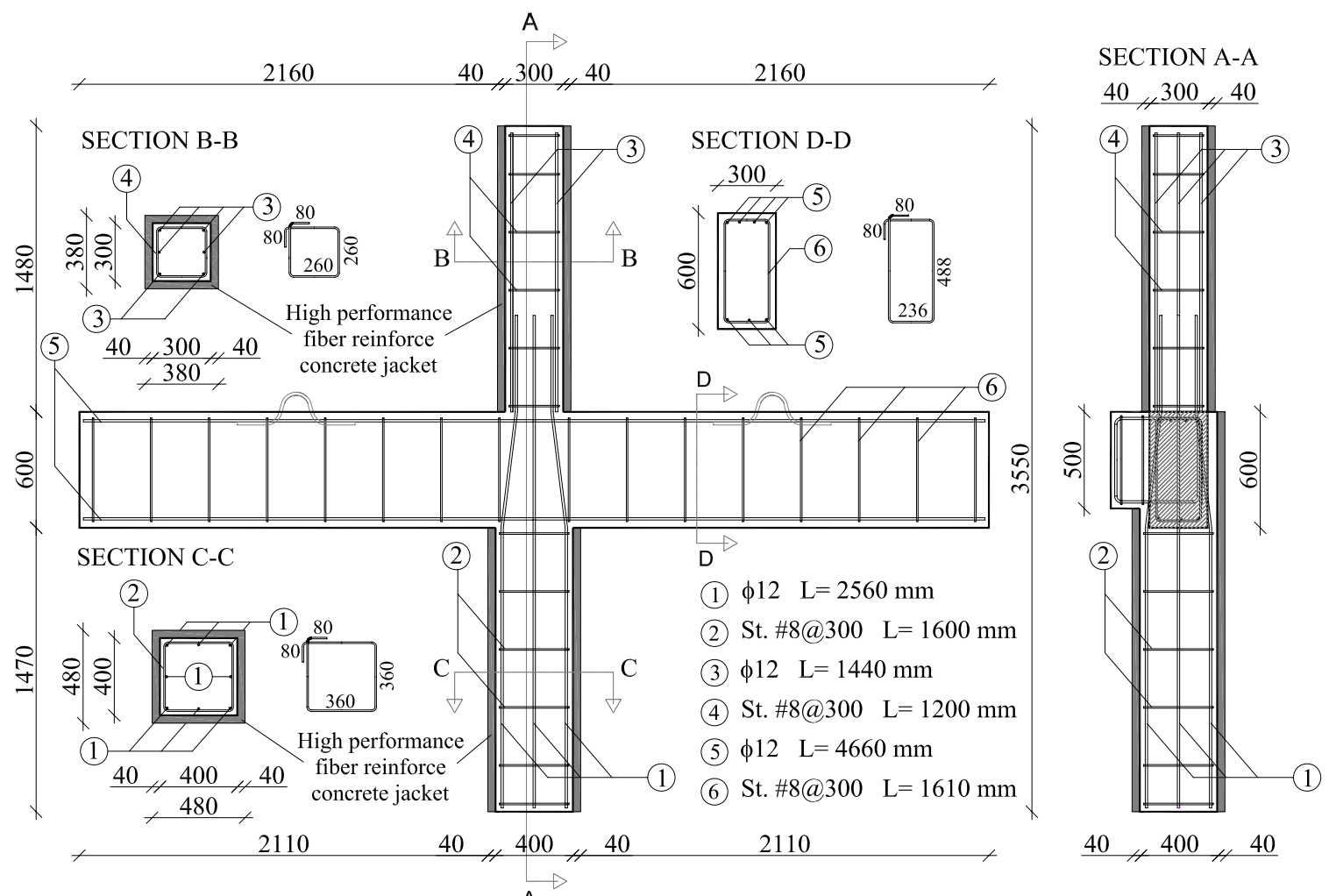

Figure 1. Specimen geometry details. 
The reinforcement and the concrete strength were typical of this kind of elements in the '60s: in the upper column there were $6 \varnothing 12 \mathrm{~mm}$ longitudinal rebars, in the lower column $8 \varnothing 12 \mathrm{~mm}$ bars and in the beam $3 \varnothing 12 \mathrm{~mm}$ longitudinal rebars at the bottom and $4 \varnothing 12 \mathrm{~mm}$ at the top.

The stirrups consisted of $\varnothing 8 \mathrm{~mm}$ stirrups spaced at $300 \mathrm{~mm}$ in the whole specimen. No stirrups were placed inside the beam-column joint, as typical in the " $60 \mathrm{~s}$. The concrete and steel strengths are specified in Table 1.

After casting and a curing period of 14 days, the column surface was sandblasted for the successive jacketing up to achieve a roughness of 1-2 $\mathrm{mm}$ to ensure a good adhesion between new and old concrete even in the absence of chemical bonding agents.

In addition, the upper faces of the two beams were levelled with a thin mortar layer and FRP sheets were applied to their upper face to enhance their negative bending moment capacity with respect to design static loads. The FRP sheets were bent at $90^{\circ}$ and glued to the column. Eventually, they were encased in the HPFRC jacket (Figg.2a, 2b).

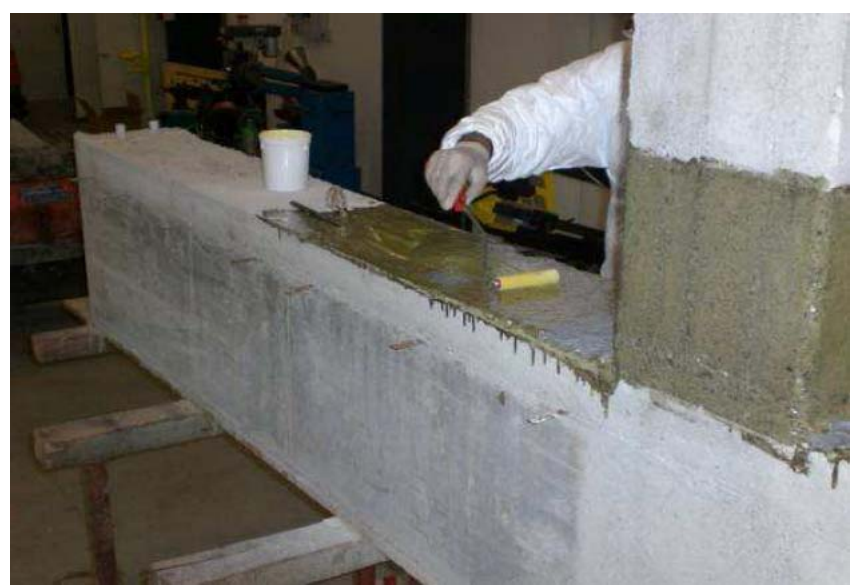

(a)

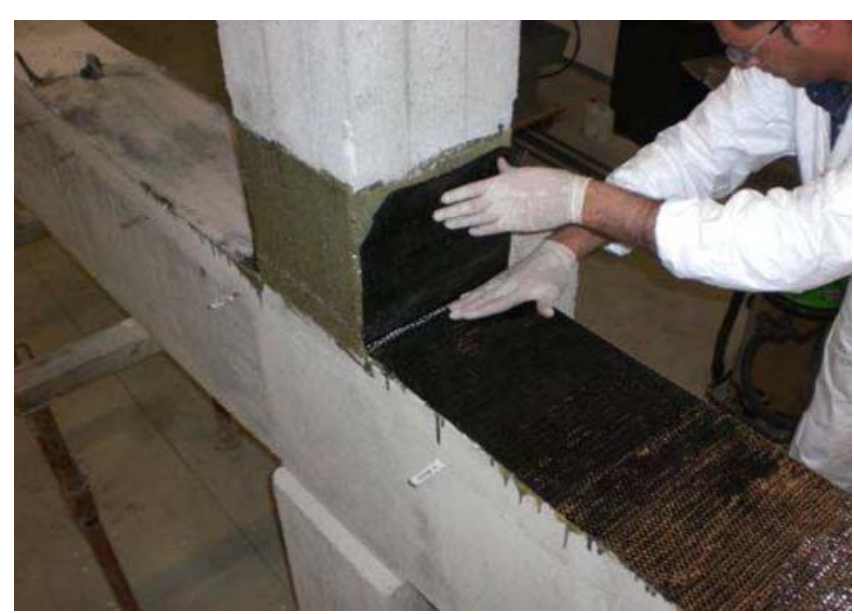

(b)

Figure 2. (a) Spreading of the bonding agent; (b) Application of the FRP sheets.

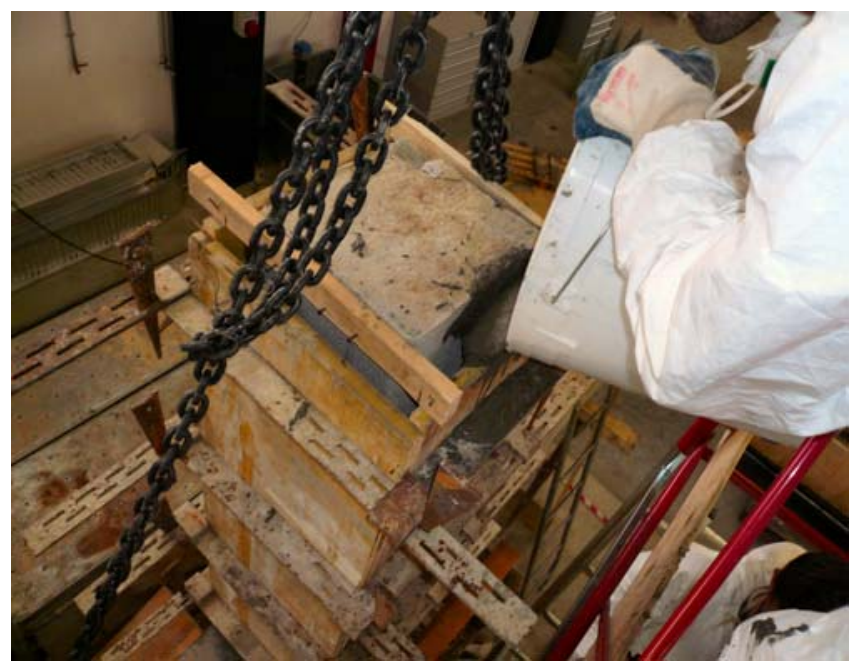

Figure 3. High performance jacket casting.

The strengthening jacket, having a thickness of $40 \mathrm{~mm}$, was eventually cast adopting a selfcompacting HPFRC (Fig.3). The mechanical properties of HPFRC are summarized in Table 1.

For the FRP sheets, the main characteristics were a high elastic modulus and a tensile strength of about $3000 \mathrm{MPa}$ (Table 1).

Table 1. Materials characteristics.

\begin{tabular}{lll}
\hline CONCRETE & & \\
\hline Average compressive strength & 17 & $\mathrm{MPa}$ \\
\hline REINFORCEMENT & & \\
\hline Average yield strength & 486 & $\mathrm{MPa}$ \\
Average tensile strength & 587 & $\mathrm{MPa}$ \\
\hline HPFRC (steel fibers) & & \\
\hline Compressive strength & 130 & $\mathrm{MPa}$ \\
Tensile strength & 6 & $\mathrm{MPa}$ \\
Elastic modulus & 42 & $\mathrm{GPa}$ \\
Fibers length & 15 & $\mathrm{~mm}$ \\
Fibers equivalent diameter & 0.18 & $\mathrm{~mm}$ \\
Fibers volume & $1.5 \%$ & \\
\hline FRP sheets & & \\
\hline Tensile stress at break & 3000 & $\mathrm{MPa}$ \\
Tensile modulus & 400 & $\mathrm{GPa}$ \\
Tensile strain at break & $1.1 \%$ & \\
Sheet thickness & 0.220 & $\mathrm{~mm}$ \\
Density & 1.8 & $\mathrm{~g} / \mathrm{cm}^{3}$ \\
Weight & 420 & $\mathrm{~g} / \mathrm{cm}^{2}$ \\
\hline
\end{tabular}

\section{TEST SET-UP}

The beam-column joint was tested using the set-up illustrated in Figure 4.

The test set-up has been designed in order to develop a hinge constraint at the base of the column as well as a roller constraint at the top of the column and at the free beam ends. Therefore, the test specimen represents a multi-storey frame part being included among its inflection points and subject to horizontal actions.

The axial load, equal to $140 \mathrm{kN}$ in accordance to the critical design load combination for the column in the building, was applied by means of two hydraulic jacks. 


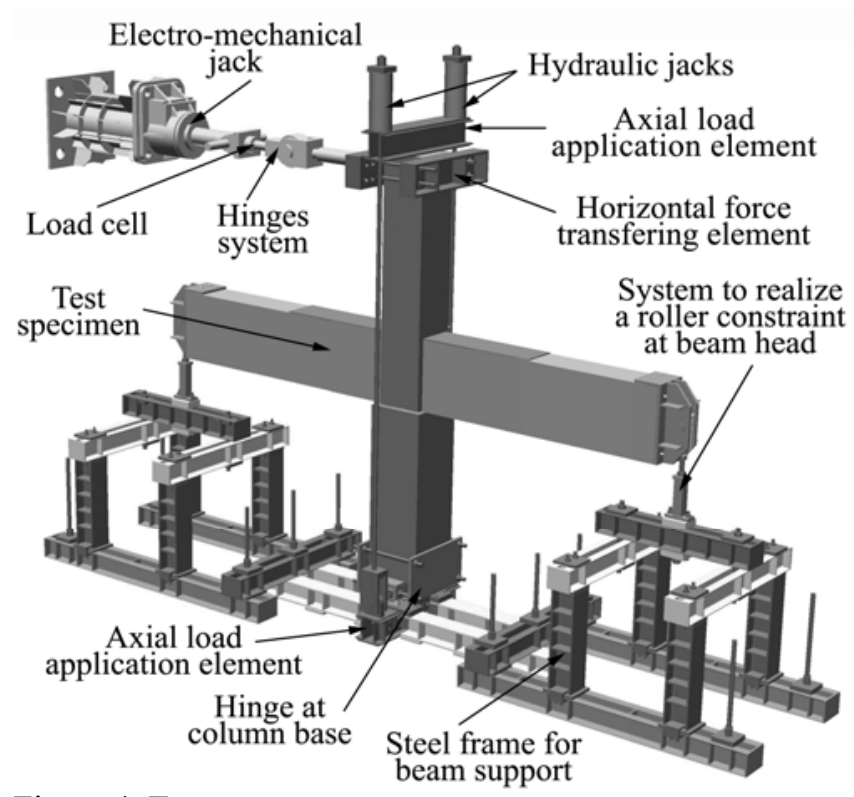

Figure 4. Test set-up.

As the test set-up and specimen geometry did not allow to apply the axial load on the column prior to jacketing, the fiber-reinforced concrete jacket and the FRP layers were applied to the specimen before the column was subjected to the axial load.

To obtain the load combination of shear and moment in the joint under serviceability loads, two forces of $24 \mathrm{kN}$ were applied at the end of the beams before the horizontal cyclic load, by applying a prestress to the threaded bars connected to the end rollers.

Eventually, a horizontal cyclic load was applied at the top of the column by means of an electro-mechanical jack fixed to the reaction wall of the laboratory.

\subsection{Measurement set-up}

In order to measure the horizontal displacements, potentiometric transducers were placed at the column top at the load application level (POS 1 and 2 in Fig.5).

The rotations between the beams and the column were measured by means of a series of potentiometric transducers (POS 3-4-5-6 in Fig.5) and the rotations of the two halves of the column were measured by the potentiometric transducers in POS 7-8-9-10.

Furthermore two devices (POS 13 and 14 in Fig.5) were placed to measure the horizontal displacements of the beams' end and two transducers (POS 15 and 16) were placed at the beams' end to measure the vertical displacements. Another transducer was provided to check any out of plane displacements.

The axial load was monitored by two instrumented bars and checked using a pressure transducer.
The horizontal load was measured by means of a load cell inserted in the hinges system, while the vertical loads were measured directly by strain gauges placed on the threaded bars at the beams' end.

\subsection{Test procedure}

Initially, a set of forces was applied aiming at simulating the serviceability loads acting on the joint (axial force on the column $\mathrm{N}=140 \mathrm{kN}$, shear force $\mathrm{V}=24 \mathrm{kN}$ and bending moment $\mathrm{M}=60 \mathrm{kNm}$ on the beams).

The horizontal load was applied with cycles characterized by increasing amplitude up to failure. The loading history of the test is shown in Figure 6.

Thirty two cycles were imposed, until a maximum displacement equal to $147 \mathrm{~mm}$ in the positive direction and $212 \mathrm{~mm}$ in the negative direction was reached.

At a drift equal to $0.5 \%, 1 \%, 1.5 \%, 2 \%$ and $2.5 \%$, three cycles were carried out. Eventually, cycles for increments of drift equal to $0.5 \%$ were applied up to failure.

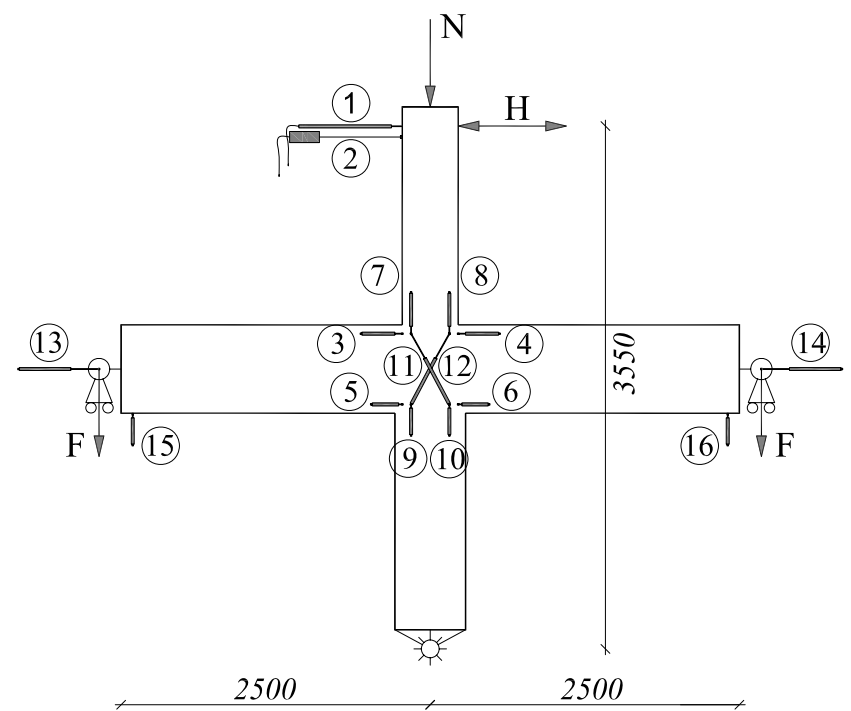

Figure 5. Displacement measurement set-up.

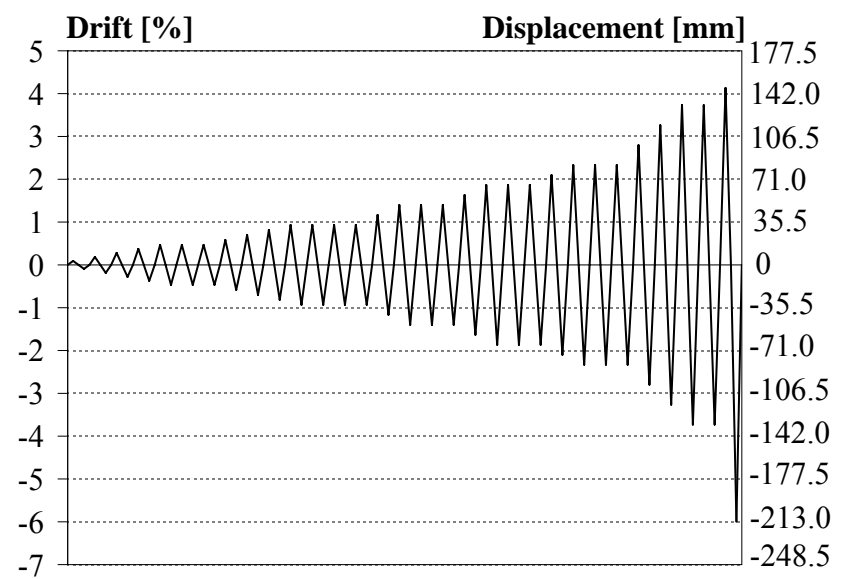

Figure 6. Loading History. 
The results in terms of horizontal load versus displacement at the level of the load application point are shown in Figure 7.

As shown in Figure 8, the joint behavior was stable up to a drift of $0.95 \%$, whereby little damage was observed in the specimen. It is pointed out that the horizontal force at a drift of $0.95 \%$ was already higher than the design force at the ultimate limit state as resulting from the code verification of the strengthened building.

At a drift equal to $0.5 \%$, compatible with the code requirement for the Damage Limit State (EN 1998-1, 2004), very little damage was observed. At this stage, a single hair-thin crack appeared in the jacket at the top column base.

During the cycle at $1.00 \%$ of drift, a localized rotation at one beam end was observed, together with the debonding of the FRP sheets along the beam. As a result, the following cycles were characterized by a pronounced pinching. The observed mechanism is explained in Figure 9.

Due to the debonding of the FRP, the sheet in compression shows a pronounced hump (point a in Fig.9); during load reversal, the tension side FRP sheet unloads rapidly, whereas the previously compressed sheet remains inactive (point $b$ ); in the middle part of the loop, both sheets are inactive, leading to a negligible stiffness of the joint (point c); eventually, the tension side FRP sheet undergoes tensile forces, leading to a stiffness recovery (point d).

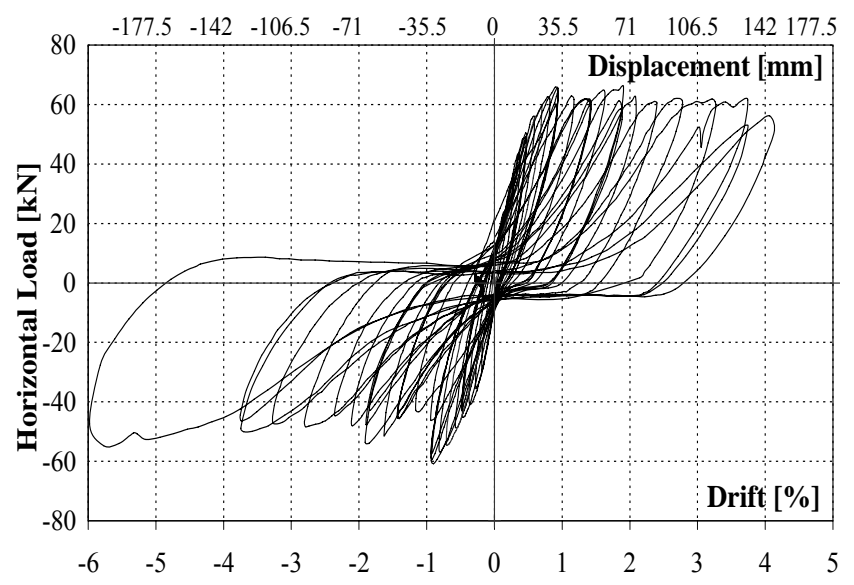

Figure 7. Horizontal load versus displacement at the load application point.

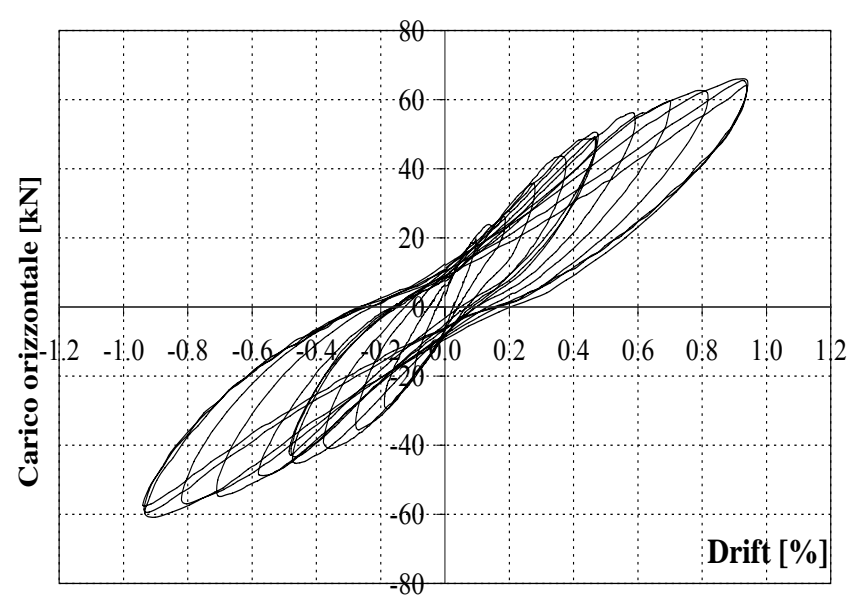

Figure 8. Horizontal load versus displacement up to a drift equal to $0.95 \%$.

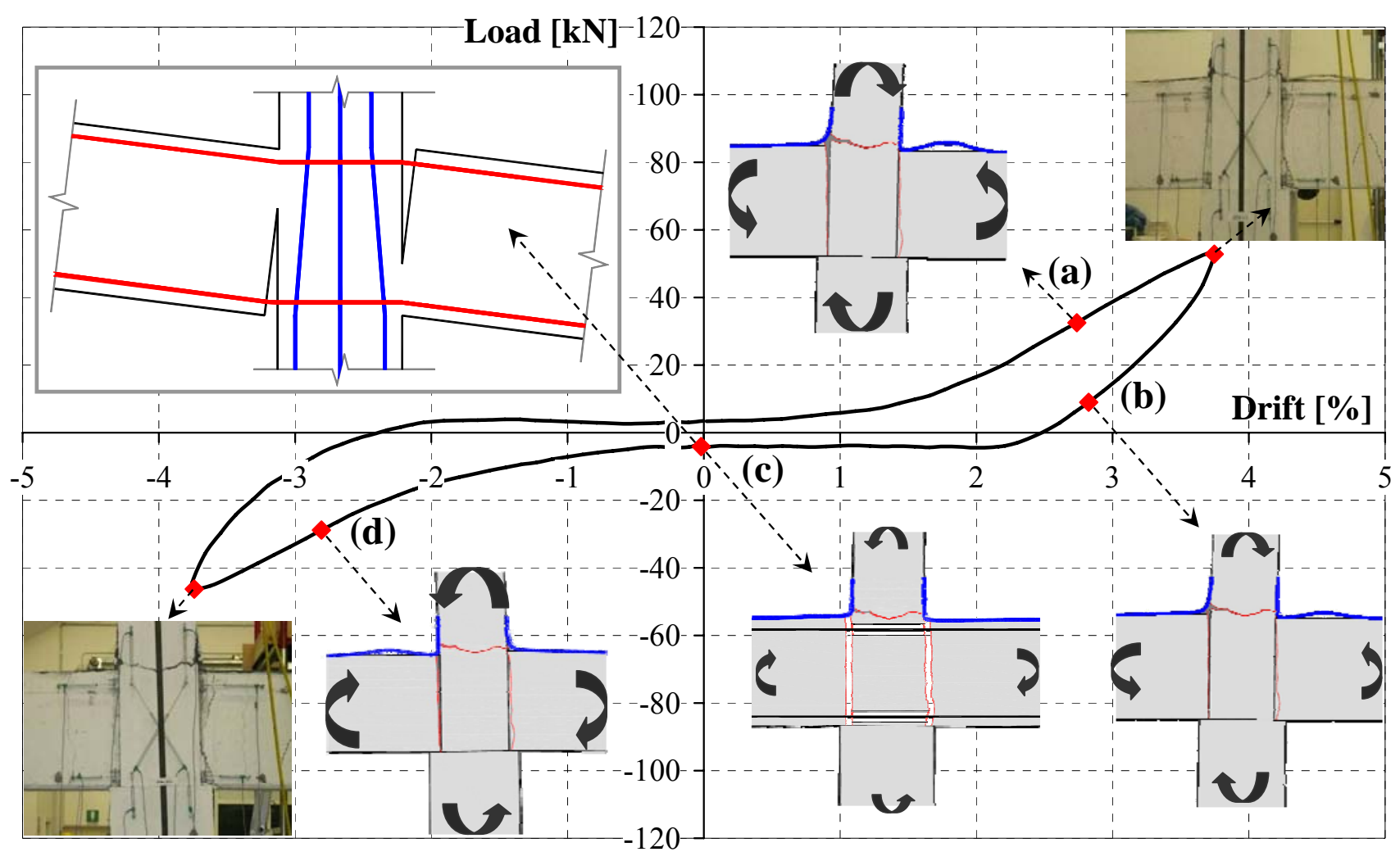

Figure 9. Mechanism leading to pinching in the cycles. 
In addition to the above mechanisms, it was observed that the cracking pattern at each face of the beam-column joint localized in a single large crack, completely open for a significant part of the cycle, leading to the conclusion that the longitudinal rebars exhibited a substantial slip (Point c in Figure 9).

The top column failed during the cycle at a drift level equal to $4 \%(142 \mathrm{~mm})$, as shown in Figure 10.

The failure was due to the concrete crushing at the top of the joint, and by the debonding of the FRP strip on the column side, leading to the detachment of the HPFRC layer encasing the FRP sheet (Fig.11). The test ended at a drift equal to $6 \%$.

It can be observed that no damage evidence was present on the joint surface while some cracks developed in the joint part where the corbel is located (Fig.12).

After the test, the high performance fiber reinforced jacket in the joint was removed in order to verify the conditions of the original concrete. As shown in Figure 13, the internal part of the joint was severely damaged.
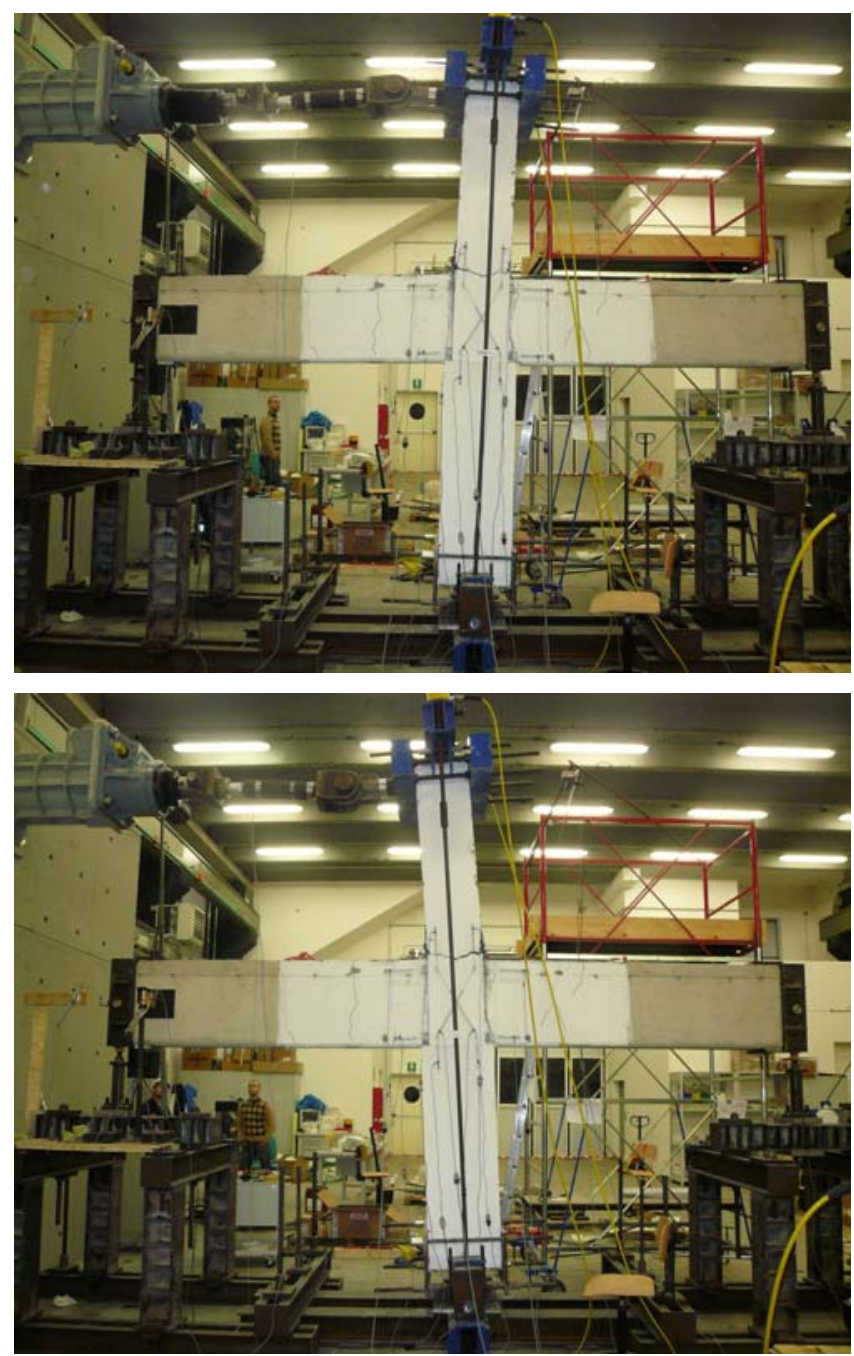

Figure 10. Specimen at a drift equal to $\pm 4 \%$.

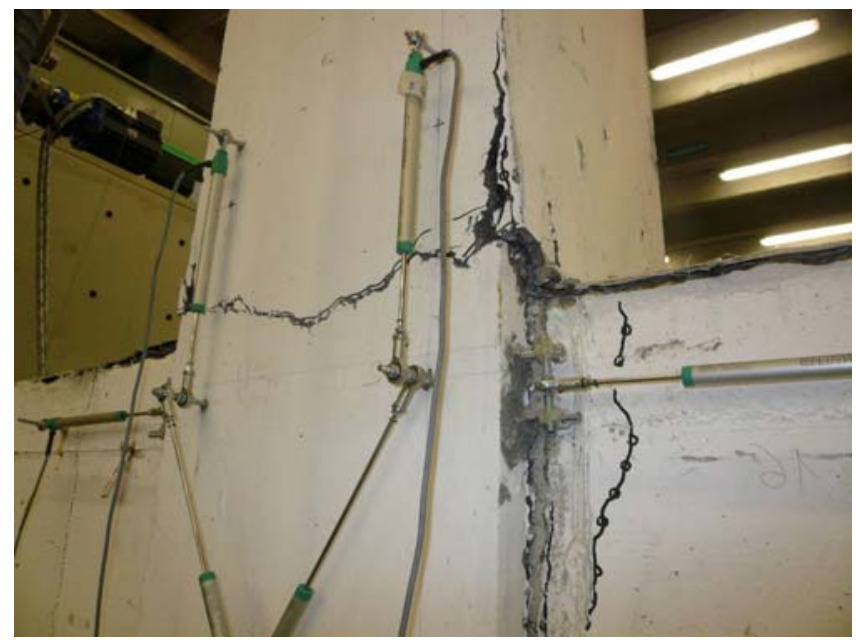

Figure 11. Failure of the column at the top.

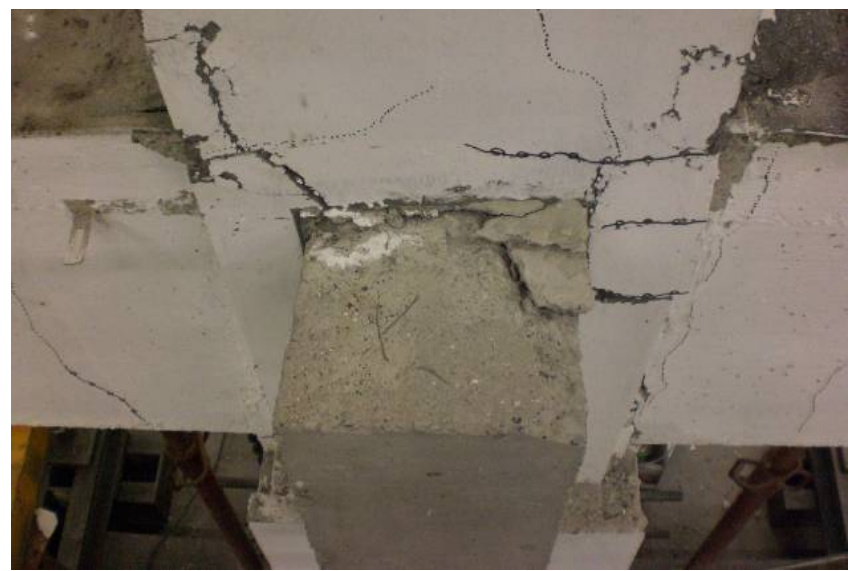

Figure 12. Cracks in the region with corbel interface.

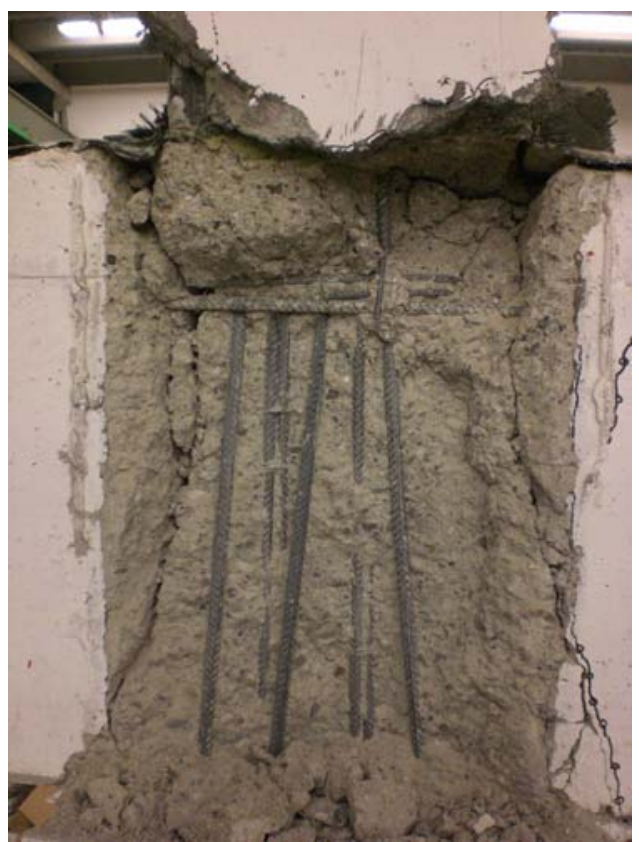

Figure 13. The joint after HPFRC jacket removal.

It was also observed that the vertical reinforcement in the beam-column joint moved during concrete casting. This anomaly justifies some inconsistencies and asymmetries in the response observed during the test. 


\section{RETROFITTED VS ORIGINAL STRUCTURAL MEMBERS}

In this section, the strength of the structural members (column, joint, and beam end section) before and after retrofitting is compared. The comparison is limited to the bearing capacity under normal forces and bending moment for the column, to the shear strength for the joint and to the flexural strength for the beam end section.

The results show that the strength of the retrofitted elements is considerably higher than that of the original members.

Concerning the column verification, the M-N envelope diagrams are drawn for the section of the upper column, before and after retrofitting. For the non retrofitted section, the M-N envelope was calculated following the classical simplified approach: Navier-Bernoulli hypothesis, tensile strength of concrete neglected, perfect bond between steel and concrete, compression in concrete modelled through a constant stress distribution (EN1992-1-1, 2004).

For HPFRC materials the same hypotheses were adopted. In addition, as the material exhibits a hardening behavior in tension, the tensile strength of concrete was considered by assuming a constant tensile stress distribution, an ultimate tensile deformation equal to $1 \%$, and perfect bond between the HPFRC jacket and the substrate (CNR-DT 204, 2006; Meda et al. 2008).

The envelope curves were computed adopting average material characteristics.

Figure 14 shows the M-N envelope for the strengthened section, compared with the unreinforced one for the upper column section of the beam-column joint, with the indication of the experimental point corresponding to a maximum bending moment of $120 \mathrm{kNm}$ for an axial load of about $140 \mathrm{kN}$.

A very large strength increase due to the jacket application is evident for both specimens.

An evaluation of the ultimate bending moment of the beam end section of the joint specimen before and after the application of FRP sheets was performed, considering the FRP as linear elastic up to failure, as specified in CNR-DT 204 (2006).

Adopting the average material characteristics, the ultimate bending moment is equal to 121 $\mathrm{kNm}$ for the unreinforced section and $216 \mathrm{kNm}$ for the strengthened section. In computing the ultimate bending moment of the strengthened section, a reduced FRP sheet ultimate tensile deformation equal to $0.66 \%$ was assumed to take into account the effect of FRP sheet debonding (CNR-DT 200, 2004).

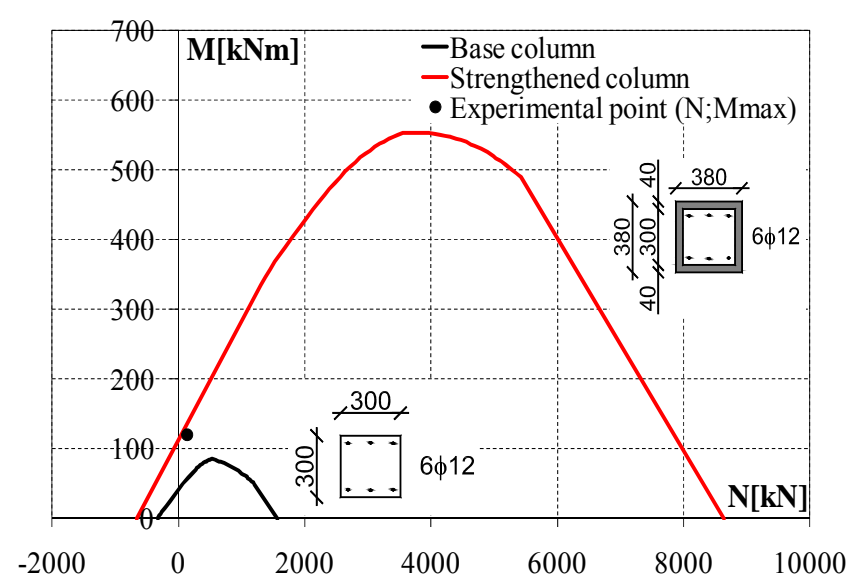

Figure 14. M-N interaction diagram for the upper column.

The strength verification of the un-retrofitted beam-column joint may be performed according to the instructions to the new Italian code (Instructions DM2008), as follows (Eq.1):

$\sigma_{n t}=\left|\frac{N}{2 A_{g}}-\sqrt{\left(\frac{N}{2 A_{g}}\right)^{2}+\left(\frac{V_{n}}{A_{g}}\right)^{2}}\right| \leq 0.3 \sqrt{f_{c k}}$

where $A_{g}$ is the column section, $N$ is the axial load in the upper column and $V_{n}$ is the total shear acting on the joint, defined as follow (Eq.2):

$V_{n}=\left(A_{s, \text { sup }}-A_{s, \text { inf }}\right) \cdot f_{y d}-V_{S d}$

For the retrofitted specimen, Equation 1 may be modified to account for the tensile strength contribution of the HPFRC as follows (Eq.3):

$$
\begin{gathered}
\sigma_{n t}=\left|\frac{N}{2 A_{T}}-\sqrt{\left(\frac{N}{2 A_{T}}\right)^{2}+\left(\frac{V_{n}}{A_{T}}\right)^{2}}\right| \leq \\
\frac{0.3 \sqrt{f_{c k}} \cdot A_{g}+\frac{f_{t k, H P F R C}}{\gamma_{H P F R C}} \cdot A_{g}^{\prime}}{A_{T}}
\end{gathered}
$$

where:

$$
\mathrm{A}_{\mathrm{T}}=\mathrm{A}_{\mathrm{g}}-\mathrm{A}_{\mathrm{g}}^{\prime}
$$

with $A_{g}$ area of the section of the non retrofitted column and $A^{\prime}{ }_{g}$ area of the HPFRC applied to the column, $\gamma_{\text {HPFRC }}$ is the safety factor for HPFRC and $F_{\text {tk,HPFRC }}$ is the tensile strength of HPFRC.

For the experimental specimen, the strength of both original and retrofitted joints was evaluated by adopting the average material properties and a unit safety factor $\gamma_{\text {HPFRC }}$. In addition, the total shear acting on the node was computed by application of Capacity Design rules as (Eq.4):

$V_{n}=\frac{M_{1}}{z_{1}}+\frac{M_{2}}{z_{2}}-V_{C}$ 


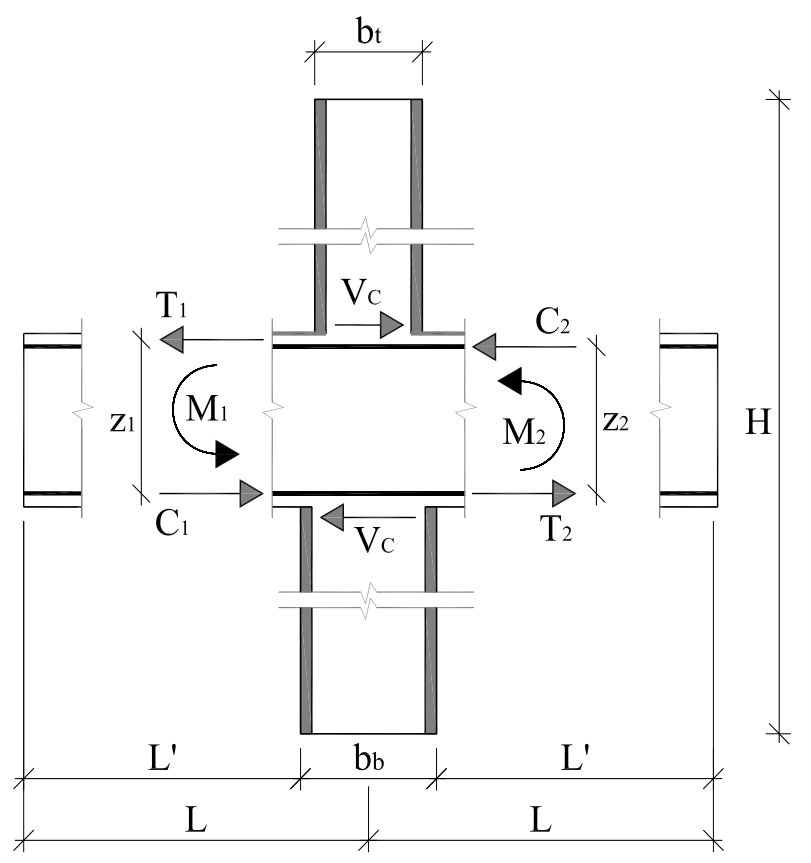

Figure 15. Forces associated to joint strength verification

where $M_{1}$ and $M_{2}$ are the resisting moments of the beams (as shown in Figure 15), $z_{1}$ is equal to $0.9 d$ for the original section and $0.9 \mathrm{~h}$ for the retrofitted section, with $h$ depth of the beam and $z_{2}$ is equal to $0.9 d$ in both cases.

The column shear $V_{c}$ is defined as (Eq.5):

$V_{C}=\left(M_{1}+M_{2}\right) \cdot \frac{L}{L^{\prime}} \cdot \frac{1}{H}$

where $L$ is the span of the beam, $L^{\prime}$ is the clear span of the beam and $H$ is the column height.

Considering the test specimen, for the unretrofitted joint, the column shear $V_{C}$ is equal to $65 \mathrm{kN}$ and the total shear acting on the node $V_{n}$ is equal to $358 \mathrm{kN}$. With an axial load of $140 \mathrm{kN}$, the stress in the joint according to Equation 1 is equal to $3.27 \mathrm{MPa}$, larger than the joint strength, equal to $1.14 \mathrm{MPa}$. Hence, the joint in the unreinforced condition is not verified.

For the retrofitted joint, the column shear $V_{C}$ is equal to $94 \mathrm{kN}$ and the total shear acting on the node $V_{n}$ is equal to $486 \mathrm{kN}$. With an axial load of $140 \mathrm{kN}$, the stress in the joint derived from Equation 3 is equal to $2.92 \mathrm{MPa}$, slightly smaller than the joint strength, equal to $2.97 \mathrm{MPa}$. In this case, the joint strength verification is satisfied.

To prove the validity of this formulation, a comparison with the experimental results is presented. To this end, the maximum negative bending moment value reached in the beams during the test, equal to $187 \mathrm{kNm}$, is taken as $M_{1}$, the corresponding positive bending moment acting on the other beam, equal to $76 \mathrm{kNm}$, is taken as $M_{2}$, and the associated axial load value, equal to $53 \mathrm{kN}$, is adopted. Applying equation 3, the stress in the joint is equal to $2.67 \mathrm{MPa}$, smaller than the joint strength, equal to $2.97 \mathrm{MPa}$. The result is consistent with the experimental evidence, as the joint did not exhibit any visible damage during the test.

\section{CONCLUSIONS}

The full-scale test presented demonstrated the efficiency of the HPFRC jacketing technique. With the application of a high performance jacket it was possible to increase the bearing capacity of the column and of the beam column joint, reaching also an adequate level of ductility.

The proposed technique results suitable for strengthening existing $\mathrm{RC}$ structures characterized by low concrete strength and low reinforcement ratios.

In addition, the possibility of applying a thin concrete jacket does not substantially change the structure stiffness, which might be relevant when the stiffness distribution of the original building should not be significantly modified.

Finally, it is important to remark that the use of a Self Compacting HPFRC jacket results in very smooth cast surfaces, such that a finishing plaster layer may be avoided, with an obvious advantage in terms of reduction in the geometry variations in the structure.

\section{ACKNOWLEDGEMENTS}

The authors wish to thank Ing. Francesca Simonelli, designer of the retrofitting intervention.

The municipality of Zagarolo (Rome) and Tecnochem Italiana s.p.a. are acknowledged for their financial support of the research.

The work reported in the present paper is a part of the research developing within the DPCReLUIS 2009-2012 project.

\section{REFERENCES}

Beschi, C., Meda, A., Riva, P., 2009. Rinforzo di pilastri con incamiciature ad elevate prestazioni, XIII Convegno ANIDIS, 28/06-2/07, Bologna, Italy.

Beschi, C., Meda, A., Riva, P., 2009. High Performance Fiber Reinforced Concrete Jacketing in a Seismic Retrofitting Application, ATC \& SEI conference on Improving the Seismic Performance of Existing Buildings and Other Structures, December 9-11, San Francisco.

CNR-DT 200, (2004). Guide for the design and construction of externally bonded FRP systems for strengthening existing structures, Italian National Research Council.

CNR-DT 204, (2006): Guide for the design and construction of fiber reinforced concrete structures, 
Italian National Research Council.

DM 2008, 2008. Technical code for structures, (In Italian), January 14.

EN 1992-1-1, 2004. EUROCODE 2: Design of Concrete Structures - Part 1-1: General rules and rules for buildings.

EN 1998-1-1, 2004. EUROCODE 8: Design structures for earthquake resistance, part 1: General rules, seismic actions and rules for buildings.

Fib Bulletin n. 24, 2003. Seismic assessment of reinforced concrete buildings.

Fib Bulletin n. 32, 2006. Retrofitting of concrete structures by externally bonded FRPs.

Fib Bulletin n. 35, 2006. Retrofitting of concrete structures by externally bonded FRPs, with emphasis on seismic applications.

Fib Report 1991. Repair and strengthening of concrete strengthening of concrete structures. Guide to good practice.

Ferrini, M., Signorini, N., Pelliccia, P., Pistola, F., Prestifilippo, V., Sabia, G., 2008. Results of the experimental campaign carried out from Tuscany Region for the evaluation of concrete strength in existing concrete buildings. Evaluation and reduction of seismic vulnerability of existing r.c. buildings, (In Italian). May 29-30, Rome, Italy.

Instructions DM2008, 2009, Instructions for the application of the new technical code for structures, (In Italian). February 22009.

Maisto, L., Meda, A., Plizzari, G.A., Rinaldi, Z., 2007. R/C beams strengthening and repair with high performance fiber reinforced concrete jacket. $4^{\text {th }}$ International Conference on the Conceptual Approach to Structural Design. June 27-29, Venezia, Italy.

Martinola, G., Meda, A., Plizzari, G.A., Rinaldi, Z., 2007. An application of high performance fiber reinforced cementitious composites for $\mathrm{R} / \mathrm{C}$ beams strengthening, FRAMCOS 6, June 18-21, Catania, Italy.

Meda, A., Plizzari, G.A., Rinaldi, Z., Martinola, G., 2008. Strengthening of $\mathrm{R} / \mathrm{C}$ existing columns with high performance fiber reinforced concrete jacket, ICCRRR 08 International Conference on Concrete Repair, Rehabilitation, and Retrofitting, November 21-23, Cape Town, South Africa. 